\section{Estudo \\ Ecidebate}

em CAStão

Dlanejamento
Revista Estudo \& Debate, Lajeado, v. 26, n. 3, 2019. ISSN 1983-036X

DOI: http://dx.doi.org/10.22410/issn.1983-036X.v26i3a2019.2146

\title{
COMPOSIÇÃO DO GASTO PÚBLICO ESTADUAL E CRESCIMENTO MUNICIPAL: APLICAÇÃO AO RIO GRANDE DO SUL, 2004-2012
}

\author{
Jacó Braatz ${ }^{1}$, Rodrigo da Rocha Gonçalves², Adelar Fochezatto ${ }^{3}$
}

\begin{abstract}
Resumo: $\mathrm{O}$ objetivo do artigo é avaliar o efeito da composição dos gastos públicos estaduais sobre o crescimento da renda per capita dos municípios do Rio Grande do Sul. Para verificar como a despesa pública estadual influencia o crescimento local, foi utilizado o modelo de Devarajan et al. (1996), que diferencia nível de gastos públicos e composição dos gastos públicos e deriva condiçóes sob as quais uma mudança na composição da despesa leva a uma maior taxa de crescimento estável da economia dividindo-se os gastos estaduais em correntes e de capital e, por funçóes: em educação, saúde e segurança. Os resultados das estimaçóes com dados em painel (panel data) indicam que os gastos estaduais nas funçóes saúde, educação e segurança, efetuados pelo estado nos municípios, foram produtivos, ou seja, contribuíram para o crescimento da renda per capita dos municípios. Por outro lado, os gastos de capital foram improdutivos, enquanto que os gastos correntes não se mostraram estatisticamente significativos.
\end{abstract}

Palavras-chave: Gastos Públicos; Crescimento Econômico; Rio Grande do Sul.

\section{COMPOSITION OF PUBLIC STATE SPENDING AND MUNICIPAL GROWTH: EMPIRICAL EVIDENCE FROM RIO GRANDE DO SUL, 2004-2012}

\begin{abstract}
The objective of this article is to evaluate the effect of the composition of state public expenditures on the per capita income growth of the municipalities of Rio Grande do Sul. To verify how state public spending influences local growth, the model of Devarajan et al. (1996), which differentiates the level of public spending and the composition of public spending and gives rise to conditions under which a change in the composition of expenditure leads to a higher rate of steady growth of the economy by dividing state expenditures into current and capital and, by functions: in education, health and safety. The results of the panel data estimates indicate that state expenditures on health, education and security carried out by the state in the municipalities were
\end{abstract}

1 Doutor em Economia pelo Programa de Pós-Graduação em Economia da Pontifícia Universidade Católica do Rio Grande do Sul - PPGE/PUCRS e Auditor Fiscal da Receita Estadual do Rio Grande do Sul.

2 Doutor em Economia pelo Programa de Pós-Graduação em Economia da Pontifícia Universidade Católica do Rio Grande do Sul - PPGE/PUCRS e professor da Universidade Federal de Rio Grande-FURG.

3 Doutor em Economia. Professor Titular da PUCRS. Pesquisador do CNPq. 
productive, that is, they contributed to the per capita income growth of the municipalities. On the other hand, capital expenditures were unproductive, while current expenditures were not statistically significant.

Keywords: Public spending; Economic Growth; Rio Grande do Sul.

\section{INTRODUÇÃO}

O Rio Grande do Sul passa por uma grave crise financeira, possivelmente, a maior de sua história. O crescimento econômico baixo e as despesas crescentes têm ocasionado déficits estruturais elevados, em média, na ordem de $15 \%$ da Receita Corrente Líquida (RCL), segundo dados da Secretaria da Fazenda estadual. Esse desequilíbrio fiscal recorrente coloca em risco as políticas públicas e as funçóes mais básicas e que sustentam a própria existência do estado.

$\mathrm{Na}$ teoria do crescimento econômico, os modelos de crescimento ditos exógenos de Solow (1956) e Swan (1955) atribuíram como secundário o papel da política fiscal, pois modificaçôes em gastos públicos e tributos possuem efeitos temporais de curto prazo, afetando apenas a velocidade de transição, mas não o nível do estado estacionário. Essas modificaçóes, portanto, não afetam o crescimento de longo prazo. Por outro lado, os modelos de crescimento endógeno explicitaram a importância da política fiscal no crescimento de longo prazo. A partir das contribuiçóes de Romer (1986), Lucas (1988) e Barro (1990), passou-se a admitir a possibilidade de que a política fiscal tenha efeitos permanentes no nível de atividade econômica. Romer (1996) realiza uma compilação dos principais modelos neoclássicos de crescimento econômico.

Barro (1990), formalizando a visão de Aschauer (1989), mostra que o estoque de capital público tem efeitos positivos sobre a produtividade, ao incorporar os gastos públicos de capital do governo na função de produção agregada. $\mathrm{O}$ autor conclui que as escolhas privadas podem não ser socialmente ótimas, pois refletem retornos de escala menor ao se comparar com os retornos sociais, os quais levam em conta também os transbordamentos de conhecimento e outras externalidades.

Muitos estudos têm sido realizados para testar os efeitos dos gastos públicos sobre o crescimento econômico. No contexto internacional, podem ser destacados os trabalhos de Ram (1986), Aschauer (1989) e Summers e Heston (1988). Para o Brasil, há uma literatura vasta sobre a relação entre gasto público e crescimento econômico, como Arraes e Teles (2000), Chagas e Toneto Jr. (2003), Rocha e Giuberti (2007), Figueiredo et al. (2003), Oliveira (2006), Oliveira et al. (2009), Dassow et al. (2011), Divino e Junior (2012), Firme e Freguglia (2013), Costa et al. (2013), entre outros. Porém, existe uma carência de trabalhos que avaliam como a composiçáo de gastos públicos de um estado da federaçáo afeta o crescimento econômico de seus municípios, logo este artigo tenta preencher essa lacuna.

Nesse contexto, é necessário avaliar a eficácia da política fiscal adotada. Para isso, a distinção proposta por Barro (1990), entre gastos produtivos (aqueles que contribuem para o crescimento econômico) e improdutivos (aqueles sem contribuiçáo significativa ao crescimento), pode ajudar na tomada de decisóes sobre recomposiçóes dos gastos e derivar 
condições sob as quais uma mudança na composição da despesa estadual leva a uma maior taxa de crescimento nos municípios do estado.

Assim, o presente trabalho tem por objetivo avaliar como a composição dos gastos públicos do estado do Rio Grande do Sul afeta o crescimento econômico de seus municípios. Busca-se verificar se gastos públicos estaduais por categoria econômica e por função de gasto são produtivos ou improdutivos. Essa análise será realizada a partir da estimação de um modelo de dados em painel, com base no modelo desenvolvido por Devarajan et al. (1996).

$\mathrm{O}$ artigo encontra-se estruturado em quatro seções, além desta introdução. $\mathrm{Na}$ seção dois, é apresentada a revisão bibliográfica, na qual se buscou ressaltar a relação entre variáveis fiscais e crescimento econômico e, também mostrar evidências empíricas da relação entre gastos públicos e crescimento econômico. Na terceira seção, são detalhados os procedimentos metodológicos e a natureza dos dados que serão utilizados nas estimaçóes, bem como os resultados e discussóes. Por fim, na quarta seçáo, apresentam-se as principais conclusóes da pesquisa.

\section{REVISÃO BIBLIOGRÁFICA}

$\mathrm{Na}$ presente seção, realiza-se uma análise teórica a respeito do papel da política fiscal nos modelos de crescimento econômico. Além disso, faz-se uma revisão de estudos empíricos sobre as relaçóes entre crescimento econômico e gastos públicos.

\subsection{Crescimento econômico e política fiscal}

O papel da política fiscal nas teorias do crescimento econômico pode ser dividido em duas vertentes: a) modelos exógenos, baseados nos trabalhos de Solow (1956), Swan (1956), Cass (1965); e b) modelos endógenos, fundamentados nas contribuições de Lucas (1988), Romer (1986, 1990), Barro (1990) e Barro e Martin (1999). Tais modelos teorizam sobre as principais variáveis que afetam a dinâmica de crescimento de um país no longo prazo, mas podem também ser aplicados a regióes.

Os modelos neoclássicos colocam a acumulação de capital como fonte propulsora do crescimento econômico. O modelo de Solow e Swan parte de uma função de produção que busca satisfazer a condição de proporçóes flexíveis no uso dos fatores. A concepção dos autores é que a produtividade marginal do capital é decrescente. Dessa forma, os países (regióes) pobres crescem mais rapidamente que os países ricos, à medida que os primeiros possuem baixas taxas de acumulação de capital e estão mais distantes do estado estacionário.

No trabalho seminal de Solow (1956), a conclusão foi que a propensão marginal a poupar determina somente a relação capital-trabalho e a velocidade do ajustamento da economia ao estado estacionário, a qual é determinada exogenamente pelas taxas de progresso tecnológico e de crescimento populacional. Além disso, percebe-se que aumentos na taxa de poupança proporcionam apenas a passagem da economia de um estado estacionário para outro. Ademais, nesses modelos, as variáveis fiscais podem afetar o rendimento dos fatores, mas não a taxa de crescimento econômico de longo prazo. 
Posteriormente, Romer (1986, 1990) e Lucas (1988), entre outros, contribuíram sensivelmente para a teoria do crescimento econômico ao tornarem o progresso tecnológico endógeno. Nesta versão, a tecnologia e o capital humano passam a ser essenciais, pois influenciam o rendimento dos fatores produtivos. Tais modelos consideram o estoque de capital físico como um índice de conhecimento acumulado e de experiências do tipo learning by doing, de forma a gerar externalidades que promovem rendimentos crescentes no uso dos fatores ou spillovers (ARRAES e TELES, 2000).

Lucas (1988) introduziu o capital humano na função de produção. Segundo o autor, quanto menor for a taxa de desconto da utilidade do consumo futuro, maior será a taxa de poupança e a acumulação de capital. Dessa forma, os investimentos em capital humano e as taxas de crescimento de longo prazo são o resultado conjunto de menores taxas de desconto das utilidades do consumo futuro.

Arraes e Teles (2000) mencionam as diferenças entre os modelos de crescimento exógenos e endógenos: a) os modelos tradicionais enfatizam o capital físico como força motriz do crescimento econômico, enquanto os modelos endógenos atribuem a mudança tecnológica e ao estoque de capital humano. Nesse caso, ambos sendo encarados como mensuraçóes do nível de conhecimento agregado do modelo de Romer (1986); b) os modelos de crescimento exógenos, ao contrário dos modelos endógenos, não consideram a possibilidade de ocorrer alteraçáo nos preços no processo de difusão do conhecimento diante de alteraçóes nos parâmetros tecnológicos da economia; c) os modelos de crescimento endógenos permitem um entendimento da dinâmica dos efeitos da política econômica, em geral, sobre diferentes patamares de crescimento, na medida em que políticas de comércio exterior, fiscal, educacional, de distribuição de renda, de formação de infraestrutura e de incentivos ao progresso tecnológico constituem-se em externalidades ao processo produtivo (spillovers); e d) os modelos de crescimento endógeno possibilitam a divergência entre os níveis de renda de economias distintas. (ARRAES e TELES, 2000, p. 757).

Barro (1990) elabora um modelo teórico com atuação governamental afetando o crescimento da economia de forma endógena. O autor desagrega os gastos em produtivos e improdutivos, almejando quantificar o tamanho ótimo de participaçáo do governo na economia para a manutenção do crescimento econômico de longo prazo. $\mathrm{O}$ autor classifica os gastos como improdutivos, quando o setor público investe em áreas que o setor privado já atua e não contribuiria significativamente para o crescimento econômico, e em produtivos, quando introduzidos à função de produção local contribuem significativamente com o crescimento econômico. Nesta concepção, a política fiscal pode afetar não só o nível de produção, mas também a taxa de crescimento de longo prazo, pois a maior parte desses modelos considera os rendimentos constantes para os fatores de produção, os quais podem ser reproduzidos por poupança e investimento, determinando o crescimento econômico de longo prazo. Por este motivo, a taxa de crescimento é tornada endógena, uma vez que é determinada pelas decisões de investimento que resultam do próprio modelo, as quais são alteradas por modificaçóes na política fiscal implementada pelos governos. 


\subsection{Crescimento econômico e gastos públicos: evidências empíricas}

A revisão empírica realizada menciona apenas alguns dos principais artigos, entretanto, a literatura que trata de tais relações é vasta. Para uma resenha, ver Lindauer e Velenchik (1992). As relaçóes entre crescimento econômico e política fiscal têm sido o foco de diversas análises empíricas no âmbito internacional e nacional, seja através do impacto dos gastos públicos, ou a partir da influência da política fiscal nos ciclos econômicos. Inicialmente, destacam-se os trabalhos que relacionam positivamente gastos públicos e crescimento econômico. Ram (1986) e Cashin (1995) analisaram essa relação e concluíram que, por meio da elevação da produtividade do setor privado, os gastos públicos conseguem elevar o crescimento econômico. Aschauer (1989) chega a resultados semelhantes para os EUA. Alguns trabalhos investigam o impacto positivo dos gastos públicos com investimento em infraestrutura, entre os quais, Easterly e Rebelo (1993), Devarajan et al. (1996) e Erenburg (1993) no contexto internacional e Ferreira (1996), Ferreira e Malliagros (1998) e Rocha e Giuberti (2007) para o Brasil. Easterly e Rebelo (1993) apontam que gastos de capital têm relação positiva com o crescimento, entretanto, não distinguem os efeitos entre países desenvolvidos e não desenvolvidos. O Anexo 1 apresenta uma síntese da literatura sobre crescimento econômico e gastos públicos, com ênfase aos trabalhos aplicados ao Brasil.

Devarajan et al. (1996) analisam países subdesenvolvidos e em desenvolvimento ao longo de 20 anos a partir de um modelo de crescimento que incorpora um gasto produtivo e outro improdutivo. Os resultados empíricos indicam que os gastos a priori considerados produtivos podem se tornar improdutivos quando são feitos em excesso, entre os quais os gastos com capital, transporte e comunicação, saúde e educação. Além disso, a pesquisa revelou que os gastos correntes estáo associados com maior crescimento econômico, principalmente nos países em desenvolvimento, que em geral, concentram seus gastos em gastos de capital.

Por outro lado, existem trabalhos que apontam como negativa a relação entre dispêndios do governo e crescimento do PIB. Como por exemplo, Aschauer e Greenwood (1985), os quais explicitam que aumentos em gastos com bens e serviços públicos reduzem o PIB, por serem financiados com tributação. Summers e Heston (1988) indicam que os gastos com defesa e educação, por serem improdutivos, comportam-se negativamente com o crescimento do produto. Por sua vez, Herrera e Blanco (2006) estimaram essa relação no curto e longo prazo e os resultados indicaram que os gastos com subsídios retraem o crescimento do produto.

No que concerne à política fiscal e aos ciclos econômicos, Escobar (2009) faz uma análise a respeito das políticas anticíclicas no Chile e, conclui que um aumento de gastos do governo não é capaz de compensar uma queda da demanda agregada. Rocha e Giuberti (2008) realizaram um estudo sobre a política fiscal dos estados brasileiros no que diz respeito ao comportamento do ciclo econômico, concluiu que as políticas estaduais eram pró-cíclicas e com certo grau de assimetria, mas que a ligação entre a assimetria e os ciclos econômicos passa a não ser sustentável após o início da vigência da Lei de Responsabilidade Fiscal.

$\mathrm{Na}$ mesma linha, Pereira e Ellery (2011) avaliam o impacto das políticas fiscais nos ciclos econômicos do Brasil e, para isso, utilizam modelos de equilíbrio geral dinâmico para uma pequena economia aberta com governo. Segundo os autores, os resultados dos 
modelos calibrados para o caso brasileiro mostram maior volatilidade do consumo e do investimento em relaçáo a volatilidade do produto, ao mesmo tempo em que a balança comercial apresenta uma volatilidade superior a de países desenvolvidos e um movimento contra cíclico. Para esses autores, a existência do sistema tributário é responsável por esses movimentos descritos e a presença dos impostos tende a amplificar o impacto e a persistência dos choques tecnológicos. Já as simulaçóes relacionadas aos impactos do sistema tributário sobre o bem-estar social da economia indicam que o imposto sobre rendimentos do capital é aquele com maior custo para a sociedade

Em relação a estudos empíricos sobre crescimento econômico, com ênfase regional ou municipal, a literatura brasileira é vasta. Os artigos utilizam diferentes metodologias, com a maior parte deles fundamentados em modelos de crescimento endógeno. A síntese da literatura nacional realizada anteriormente, no entanto, indica que existe uma carência de estudos que avaliam o impacto de gastos públicos de um estado sobre o crescimento econômico de seus municípios. Por isso, esse artigo tenta suprir tal lacuna estimando um modelo econométrico em painel, que avalia como a composição da despesa pública estadual afeta o crescimento econômico dos municípios do estado do Rio Grande do Sul.

\section{METODOLOGIA E RESULTADOS}

A presente seção tem por objetivo destacar a metodologia aplicada na pesquisa, bem como apresentar a fonte e a natureza dos dados e, logo após, os resultados empíricos e discussóes. Na primeira subseção, destaca-se o modelo econométrico a ser estimado e, na segunda seção, a análise dos resultados.

\subsection{Especificaçáo do modelo e base de dados}

Vislumbrando analisar empiricamente o impacto da composiçáo dos gastos públicos estaduais sobre o crescimento econômico dos municípios gaúchos no período compreendido entre 2004 e 2012, será utilizada a metodologia de dados em painel. Esta técnica de agregação de séries temporais e dados em corte transversal permite a estimação mais completa e eficiente de modelos econométricos. Todavia, a estimação de tais modelos se torna mais complexa na medida em que aumenta a heterogeneidade entre as unidades de corte transversal (WOOLDRIDGE, 2002).

O modelo de dados em painel admite o uso de dois estimadores com distintas propriedades: se os efeitos não estão correlacionados com as variáveis explicativas, o estimador de efeitos aleatórios (EA) é consistente e eficiente. Caso os efeitos estejam correlacionados com as variáveis explicativas, o estimador de Efeitos Fixos (EF) é consistente e eficiente, enquanto o de (EA) é não consistente. Através da verificação do teste de Hausman, podese escolher uma ou outra especificação do modelo. A estatística deste teste terá a hipótese nula de que o estimador de EA é o mais adequado, com distribuição assintótica de um quiquadrado com $k$ graus de liberdade.

O estudo baseia-se em um modelo genérico, especificado da seguinte maneira:

$$
g_{i t}=a_{i t}+\beta_{k} X_{i t}+u_{i t}
$$


onde: $i=1, \ldots, 497$ representa os municípios do Rio Grande do Sul; $t=2004, \ldots$, 2012 representa um ano entre 2004 e 2012; $k=$ número de variáveis explicativas; $a=$ constante estimada; $\beta$ = parâmetros estimados; $g_{i t}$ representa a taxa de crescimento referente à variável dependente de interesse; $X_{i t}$ é o vetor de variáveis explicativas, composto pelos diferentes tipos de gastos públicos do Estado do Rio Grande do Sul; e $u$ é o termo de erro.

Tendo como base o modelo Devarajan et al. (1996), recorreu-se à utilizaçáo de um modelo de dados em painel, considerando o período de 2004 a 2012 e os 497 municípios do Rio Grande do Sul. Todas as variáveis foram transformadas em logaritmo, a fim de tratar as variáveis explicativas como elasticidades, tornando os resultados interessantes para formulação de política econômica. A variável endógena utilizada é a taxa anual de crescimento do PIB per capita $\left(g_{i}\right)$. Esta variável representa o crescimento econômico e foi obtida junto a Fundação de Economia e Estatística (FEE).

A matriz de variáveis independentes $X_{i t}$ é composta por: a) LN(GCORRENTES/ GT); b) LN(GCAPITAL/GT; c) LN(GSAÚDE/GT); d) LN(GSEGURANÇA/GT); e) LN(GEDUCAÇÃO/GT e f) LN(GT/PIB). No quadro 1, detalha-se as variáveis e suas respectivas fontes.

Quadro 1- Descrição e fonte das variáveis

\begin{tabular}{|c|c|c|}
\hline Siglas & Descriçãao & Fonte \\
\hline $\begin{array}{l}\text { LN(GCORRENTES/ } \\
\text { GT) }\end{array}$ & $\begin{array}{l}\text { LN da proporção do gasto público corrente em relaçáo ao } \\
\text { gasto total do estado no município i. }\end{array}$ & SEFAZ-RS \\
\hline LN(GCAPITAL/GT) & $\begin{array}{l}\text { LN da proporção do gasto público de capital em relação } \\
\text { ao gasto total do estado no município i. }\end{array}$ & SEFAZ-RS \\
\hline LN(GSAÚDE/GT) & $\begin{array}{l}\text { LN da proporção do gasto público na funçáo "educação" } \\
\text { em relação ao gasto total do estado no município i. }\end{array}$ & SEFAZ-RS \\
\hline $\begin{array}{l}\text { LN(GSEGURANÇA/ } \\
\text { GT) }\end{array}$ & $\begin{array}{l}\text { LN da proporção do gasto público na função "segurança" } \\
\text { em relaçáo ao gasto total do estado no município i. }\end{array}$ & SEFAZ-RS \\
\hline $\begin{array}{l}\text { LN(GEDUCAÇÃO/ } \\
\text { GT) }\end{array}$ & $\begin{array}{l}\text { LN da proporção do gasto público na funçáo "educação" } \\
\text { em relação ao gasto total do estado no município i. }\end{array}$ & SEFAZ-RS \\
\hline LN(GT/PIB) & $\begin{array}{l}\text { LN da razão entre o gasto total do governo gaúcho no } \\
\text { município i e o PIB do mesmo município i. }\end{array}$ & $\begin{array}{l}\text { SEFAZ-RS } \\
\text { FEE-RS }\end{array}$ \\
\hline LN(CRESCPIB) & LN da taxa de crescimento do PIB no município i. & FEE \\
\hline
\end{tabular}

Fonte: Elaboração dos autores, com dados do banco de dados interno da SEFAZ/RS - Cubos DW.

Cabe mencionar que os gastos foram divididos de acordo com sua classificação: i) categoria econômica: gastos correntes e gastos de capital; e ii) gastos por funçôes: educação, saúde e segurança, as quais representam em torno de $28 \%$ do orçamento do estado do Rio Grande do Sul, desconsiderando o gasto de pessoal inativo nessas áreas (aposentados e pensionistas), o qual é classificado na função "previdência social". Além disso, na tabela 1, demonstram-se as estatísticas descritivas das variáveis utilizadas nas estimaçōes por categoria econômica e por função. 
Tabela 1: Estatísticas descritivas das variáveis utilizadas nas estimações

\begin{tabular}{lccccc}
\hline \multicolumn{1}{c}{ Variáveis } & Obs. & Média & Desvio Padrão & Min. & Máx. \\
\hline LN(GCORRENTES/ & 4.455 & $-0,7480$ & 0,0971 & $-1,5700$ & 0,2300 \\
GT) & 4.446 & $-1,1154$ & 0,5330 & $-2,7800$ & $-0,1000$ \\
LN(GCAPITAL/GT) & 4.455 & $-0,5771$ & 0,2885 & $-2,9100$ & 0,8000 \\
LN(GSAÚDE/GT) & 3.835 & $-1,8770$ & 0,8017 & $-4,7000$ & $-0,5000$ \\
LN(GSEGURANÇA/ & 4.455 & $-0,6972$ & 0,2913 & $-2,5100$ & $-0,5000$ \\
GT) & 4.455 & $-1,9997$ & 0,2768 & $-3,3800$ & $-0,2200$ \\
LN(GEDUCAÇÃO/GT) & 4.455 & 2,1546 & 0,1430 & 1,6300 & 2,8000 \\
LN(GT/PIB) & & & & & \\
LN(CRESCPIB) &
\end{tabular}

Fonte: Elaboração dos autores.

Para a avaliação dos efeitos da composição do gasto sobre a renda per capita dos municípios, foram testadas diferentes defasagens dos gastos públicos, sendo escolhida a de quatro anos, pois apresentou melhores resultados. Esta defasagem também evita potenciais problemas de endogeneidade e de causalidade reversa entre gasto público e crescimento econômico. Cabe mencionar, que foram estimados modelos de painel dinâmico, porém como os resultados foram inconsistentes e os instrumentos não se mostraram válidos, optou-se somente pela estimação de modelos de painel estático com erros robustos, visando corrigir possíveis problemas de autocorrelação e heterocedasticidade.

\subsection{Análise dos resultados}

A seguir, faz-se a exposição dos resultados obtidos com suas respectivas análises dos modelos: agrupado, de efeitos fixos (EF) e de efeitos aleatórios (EA). As Tabelas 2 e 3 apresentam os resultados das regressóes por categoria econômica e função de gasto. A definiçáo do melhor modelo entre os modelos de dados em painel testados ocorreu levando em consideração: a) o teste F; b) o teste de Hausman; e c) equilíbrio dos dados no painel. Os critérios anteriores indicaram o modelo de efeitos fixos como o mais adequado, então os resultados a serem explorados são deste modelo, com erros robustos.

Os resultados explicitados na Tabela 2 dos modelos de painel para a composição de gastos por categoria demonstram que a variável gastos correntes não se mostrou estatisticamente significante em nenhuma das estimaçóes. Não se tem evidências empíricas, portanto, se os gastos públicos efetuados pelo estado, em seus municípios, são produtivos ou improdutivos no período. Alguns trabalhos também não encontraram relação estatisticamente significante entre gastos públicos e crescimento econômico, entre os quais, Srinivasan (1985) e Bhagwati (1982), Kormendi e Meguire (1985), Herrera e Blanco (2006) e, especificamente, para gastos correntes, Easterly e Rebelo (1993).

No que tange a não significância dos gastos públicos correntes sobre o crescimento econômico, o resultado não surpreende, uma vez que a literatura brasileira aponta evidências sistemáticas de que os gastos correntes não têm relação com a taxa de crescimento (ROCHA 
e GIUBERTI, 2007). No caso específico do Rio Grande do Sul, os gastos com pessoal e encargos representam mais de $50 \%$ do total, e são considerados como improdutivos na maior parte dos estudos empíricos, ou seja, não contribuem com o crescimento.

Em relação aos gastos de capital, esperava-se um efeito significativo e positivo. Entretanto, o resultado foi estatisticamente significativo e negativo, evidenciando que este tipo de gasto foi improdutivo no período analisado. Tal fato pode ser explicado pela incapacidade do governo gaúcho em realizar investimentos públicos, principalmente nos últimos anos e também pelo fato de boa parte desses gastos serem financiados via endividamento. Outra provável explicação para esse fato são as baixas taxas de investimento frente ao orçamento geral do estado, que estagnaram nesse período e representam a mínima parte da composição de gastos de capital e, dadas as baixas taxas, os possíveis efeitos seriam limitados.

Cabe mencionar, que a maior parte das evidências empíricas indica relação positiva entre investimentos públicos e taxa de crescimento do PIB, nesse sentido, Musgrave (1980) e Wagner (1983) mencionam a importância do fomento ao investimento do setor público, sendo um importante fator nos primeiros estágios de desenvolvimento dos países e regióes. Tal fato se dá em virtude de que, nesta fase inicial existe a necessidade de investimentos, especialmente, em infraestruturas sociais e econômicas, tais como transporte, estradas, saneamento e educação, os quais o Rio Grande do Sul apresenta carência histórica.

Tabela 2: Resultados do modelo de composição dos gastos públicos por categoria econômica, 2004-2012

\begin{tabular}{lccc}
\hline VARIÁVEIS & $\begin{array}{c}\text { Modelo Agrupado } \\
\text { Robusto } \\
(\mathbf{1})\end{array}$ & $\begin{array}{c}\text { Modelo de EF } \\
\text { Robusto } \\
\mathbf{( 2 )}\end{array}$ & $\begin{array}{c}\text { Modelo de EA } \\
\text { Robusto } \\
(\mathbf{3})\end{array}$ \\
\hline LN(GCORRENTES/GT) & -0.0084 & -0.0232 & 0.0015 \\
LN(GCAPITAL/GT) & $(-0.28)$ & $(0.51)$ & $(0.04)$ \\
LN(GT/PIB) & $-0.0843^{* * *}$ & $-0.0981^{* * *}$ & $-0.0894^{* * *}$ \\
& $(-14.90)$ & $(-13 . .21)$ & $(-13.42)$ \\
Constante & $0.0322^{* *}$ & 0.0385 & $0.0336^{*}$ \\
& $(4.05)$ & $(2.14)$ & $(2.45)$ \\
Observaçóes & $2.1244^{* * *}$ & $2.1239^{* * *}$ & $2.1222^{* * *}$ \\
Teste F (Prob.) & $(118.76)$ & $(57.40)$ & $(73,08)$ \\
$\mathrm{R}^{2}$ & 4444 & 4444 & 4444 \\
Municípios & 0.0000 & 0.0000 & 0.0000 \\
Teste de Hausman (Prob.) & 0.0895 & 0.1287 & 0.1286 \\
\hline \multicolumn{4}{c}{497} \\
\end{tabular}

Fonte: Resultados da pesquisa.

Nota: $\mathrm{LN}(\mathrm{GCORRENTES/GT)}=\log$ natural dos gastos correntes sobre o gasto total; LN(GCAPITAL/GT) = log natural dos gastos de capital sobre o gasto total; e LN(GT/PIB $)=\log$ natural do gasto total sobre o PIB . 
Os resultados explicitados na Tabela 3, que mostram os modelos estimados para a composição de gastos públicos por funções, demonstram que os gastos com saúde, segurança e educação se mostraram estatisticamente significantes em todos os modelos. Isso permite afirmar que esses gastos foram produtivos, ou seja, contribuíram para o crescimento do PIB per capita municipal.

Inicialmente, os resultados do modelo 2 da Tabela 3 indicaram que a composição dos gastos em segurança pública do Estado nos municípios foi produtiva, ou seja, teve efeito positivo na taxa de crescimento do PIB per capita dos municípios. O aumento em $1 \%$ na proporção gasto em segurança pública no gasto total gera a elevação do crescimento econômico dos municípios gaúchos em $0,048 \%$. Isso é valido porque a maior parte dos serviços de segurança pública é prestada pelo Estado e a manutenção de um ambiente seguro favorece o desempenho da atividade econômica. Esses resultados estáo de acordo com evidências empíricas, em especial Rocha e Giuberti (2007).

Percebe-se ainda que a composiçâo dos gastos com saúde do estado do Rio Grande do Sul para seus municípios foi produtiva, ou seja, tiveram efeito positivo na taxa de crescimento do PIB per capita dos municípios gaúchos, esses resultados são semelhantes ao trabalho de Figueiredo et al. (2003). Tal efeito é oriundo do impacto indireto que fatores relacionados a saúde exercem sobre o capital humano, à medida que os dispêndios do governo estadual para os municípios são relevantes para a manutenção dos serviços do setor, o acesso maior a tais serviços impacta no aumento da produtividade dos trabalhadores.

Os resultados do modelo 2 da Tabela 3 também indicam que a proporçáo do gasto em educaçáo em relaçáa ao gasto total foi produtiva, ou seja, contribuiu para a elevaçáo do crescimento econômico dos municípios gaúchos. Resultados semelhantes para o Brasil também foram encontrados em Arraes e Teles (2000), Oliveira (2006) e Costa et al. (2013). O efeito positivo da educação é fato estilizado na literatura do crescimento econômico, pelo impacto direto que a melhora do capital humano exerce sobre a produtividade do trabalhador, porém nem sempre é garantido que o gasto em educação eleve sua qualidade.

Tabela 3: Resultados do modelo de composição dos gastos públicos por função do gasto, 2004-2012

\begin{tabular}{lccc}
\hline VARIÁVEIS & $\begin{array}{c}\text { Modelo Agrupado } \\
\text { Robusto } \\
(\mathbf{1})\end{array}$ & $\begin{array}{c}\text { Modelo de EF } \\
\text { Robusto } \\
(\mathbf{2})\end{array}$ & $\begin{array}{c}\text { Modelo de EF } \\
\text { Robusto } \\
(\mathbf{3})\end{array}$ \\
\hline LN(GSAÚDE/GT) & $0.0726^{* * *}$ & $0.0885^{* * *}$ & $0.0816^{* * *}$ \\
& $(7.93)$ & $(6.10)$ & $(6.37)$ \\
LN(GEDUCAÇÃO/GT) & $0.1396^{* * *}$ & $0.1873^{* * *}$ & $0.1610^{* * *}$ \\
& $(18.74)$ & $(14.58)$ & $(14.43)$ \\
LN(GSEGURANÇA/GT) & $0.0449^{* * *}$ & $0.0483^{* * *}$ & $0.0469^{* * *}$ \\
LN(GT/PIB) & $(17.40)$ & $(13.26)$ & $(14.44)$ \\
& 0.0008 & -0.0171 & -0.0072 \\
Constante & $(0.10)$ & $(-1.17)$ & $(-0.57)$ \\
& $2.3778^{* * *}$ & $2.3918^{* * *}$ & $2.3864 . *^{* * *}$ \\
& $(141.82)$ & $(82.06)$ & $(94.56)$
\end{tabular}




\begin{tabular}{lccc}
\hline VARIÁVEIS & $\begin{array}{c}\text { Modelo Agrupado } \\
\text { Robusto } \\
(\mathbf{1})\end{array}$ & $\begin{array}{c}\text { Modelo de EF } \\
\text { Robusto } \\
(\mathbf{2})\end{array}$ & $\begin{array}{c}\text { Modelo de EF } \\
\text { Robusto } \\
\text { (3) }\end{array}$ \\
\hline Observaçôes & 3831 & 3831 & 3831 \\
$\mathrm{R}^{2}$ & 0.1467 & 0.2048 & 0.2032 \\
Municípios & 497 & 497 & 497 \\
Hausman (Prob.) & 0.0001 & 0.00001 & \\
\hline \multicolumn{4}{c}{ Standard errors in parentheses } \\
& \multirow{2}{*}{$\mathrm{p}<0.01,{ }^{* *} \mathrm{p}<0.05,{ }^{*} \mathrm{p}<0.1$} & \\
\hline
\end{tabular}

Fonte: Resultados da pesquisa.

Nota: LN(GSAÚDE/GT) = log natural dos gastos em saúde sobre o gasto total; LN(GEDUCAÇÃO/GT) = $\log$ natural dos gastos em educação sobre o gasto total; LN(GSEGURANÇA/GT) = log natural dos gastos em segurança sobre o gasto total; e LN(GT/PIB) = log natural do gasto total sobre o PIB.

Assim, no caso dos dispêndios do governo gaúcho, percebe-se que a composição do gasto público dividido por funçóes, mostrou-se produtiva e também se destaca a importância dos gastos públicos com educação, que apresentaram os maiores coeficientes nas estimaçóes, o que demostra que esse tipo de gasto é de grande importância para o crescimento do PIB per capita dos municípios. O fato do gasto total (GT/PIB) ser negativo, embora não tenha se mostrado significativo, pode estar indicando que, no global, os gastos públicos não estão sendo produtivos na promoçáo do crescimento econômico.

\section{CONCLUSÃO}

Este artigo avaliou como a composição de gastos públicos do estado Rio Grande do Sul afetou o crescimento econômico de seus municípios entre 2004 e 2012. Buscouse verificar se os gastos públicos divididos por categoria econômica e por função de gasto foram produtivos ou improdutivos. Para isso, estimou-se um modelo de dados em painel, com base no modelo desenvolvido por Devajaran et al. (1996).

A literatura econômica tem demonstrado com exaustão a necessidade de melhorar a alocação do gasto público, de forma a gerar resultados significativos e criar externalidades positivas sobre o nível de atividade econômica, sobre a distribuição da renda e o crescimento econômico. Porém, não existe um consenso, na literatura empírica, sobre o efeito dos gastos públicos totais sobre o crescimento econômico. Percebe-se que os resultados dependem das características de cada economia e do período analisado, porém para gastos em investimentos e educação há certos consensos na literatura empírica de que seriam produtivos.

No que diz respeito à relação entre a composição do gasto público estadual e o crescimento do PIB municipal, foram encontrados os seguintes resultados: a) a relação entre os gastos correntes do governo estadual e o crescimento econômico dos municípios não foi significativa; b) a relação entre os gastos de capital do governo estadual e o crescimento dos municípios gaúchos foi negativa; e c) a relação entre gastos públicos estaduais nas funçóes educação, saúde e segurança e o crescimento econômico dos municípios foi positiva.

Isso demonstra que, de modo geral, ao se considerar a classificação econômica dos gastos, a despesa pública estadual pouco tem contribuído para o crescimento econômico 
dos municípios e no caso da despesa de capital estaria contribuindo negativamente. Essa contribuição negativa dos gastos de capital pode ser explicada pela precária situação financeira do Rio Grande do Sul, que enfrenta queda nos já baixos valores investidos ao longo dos últimos anos.

Entretanto, analisando o gasto público pelas funçóes de gastos, houve efeitos positivos e significativos em todas as funçóes avaliadas, como preconiza a literatura da área. Os resultados encontrados indicam a importância dos dispêndios em educação, saúde e segurança pública para o crescimento econômico dos municípios do Rio Grande do Sul. Porém, percebe-se a necessidade de melhora na produtividade da execução do gasto público estadual global. Nesse sentido, recomenda-se a formulação de políticas públicas de longo prazo direcionadas a gestão dos recursos públicos.

Considerando que a política fiscal é um dos principais instrumentos que o estado tem de promover de alguma forma a melhoria na vida das pessoas, seja pelo crescimento econômico, seja pela melhoria na distribuição de renda, caberia no futuro um estudo que levasse em consideração se o gasto público estadual está de alguma forma contribuindo com a redução das desigualdades sociais, ou quanto a sua progressividade. Se assim for, significa que em relação a alguma variável de controle, por exemplo, PIB per capita, o Estado estaria gastando mais naqueles municípios de menor renda ou elevando a composição do gasto em saúde, em municípios que apresentam, por exemplo, alto índice de mortalidade infantil.

Além disso, o trabalho se limitou pela disponibilidade dos dados, acessíveis apenas a partir de 2004, para o PIB e PIB per capita dos municípios. Entende-se que uma expansão da amostra e a inserção de outras funçóes de gastos poderia contribuir com a temática, o que fica como sugestão para análises futuras.

\section{REFERÊNCIAS}

ARRAES, R. A. e TELES, V. K. (2000). Endogeneidade versus Exogeneidade do Crescimento Econômico: Uma Análise Comparativa entre Nordeste, Brasil e Países Selecionados. Revista Econômica do Nordeste, V. 31, Edição especial, p. 754-776.

ASCHAUER, D. (1989). Is public expenditure productive? Journal of Monetary Economics, V. 23, p.177-200.

ASCHAUER, D.; GREENWOOD, J. (1985). Macroeconomic effects of fiscal policy. Carnegie- Rochester Series on Public Policy, V.23, p.91-138.

BARRO, R J. (1990). Government spending in a simple model of endogenous growth. The Jornal of Political Economy, V. 98, n.5, p.103-125.

BARRO, R. J.; SALA-I-MARTIN, X. (1999). Economic Growth. MIT Press.

BHAGWATI, J. (1982). Directly unproductive profit-seeking DUP activities. Journal of Political Economy, V. 90, n. 5, p. 988-1002. 
CASHIN, P. (1995). Government Spending, Taxes and Economic Growth. IMF Staff Papers, V. 42, n. 2, p. 237-269.

CASS, D. (1965). Optimum Growth in an Aggregative Model of Capital Accumulation,” Review of Economic Studies, V. 32, 233-240.

CHAGAS, A., TONETO J. R. (2003). Fatores determinantes do crescimento local - Evidências a partir de dados dos municípios brasileiros para o período 1980-1991. Pesquisa e Planejamento Econômico, V. 33, agosto.

COSTA, R. F. R.; LIMA, F. S.; SILVA, D. O, D. (2013). Política fiscal local e crescimento econômico: um estudo em painel para os municípios, 2013. Revista Econômica do Nordeste, V. 44, n. 01, p. 94-112.

DEVARAJAN, S.; SWARROP, V.; ZOU, H. (1996). The composition of public expenditure and economic growth. Journal of Monetary Economics, V.37, p.313-344.

DASSOW, C.; COSTA, R. M. G. (2011). Econômico Municipal em Mato Grosso: Uma Análise de Convergência de Renda. Revista Brasileira de Economia, V. 65 n. 4, p. 359-372.

DIVINO, J. A.; JUNIOR, R. L. S. (2012). Composição dos Gastos Públicos e Crescimento Econômico dos Municípios Brasileiros. Revista Economia, V. 13, n. 2.

EASTERLY, W.; REBELO, S. (1993). Fiscal policy and economic growth: an empirical investigation. Journal of Monetary Economics, V.32, 417-458.

ESCOBAR, F. LUIS, E. (2009). Chile: Políticas contra cíclicas para las crisis, 2009. Disponível em: < http:/www.archivochile.com/Debate/crisis_08_09/crisis00108.pdf > . Acesso em: 18/03/2015.

ERENBURG, S. J. (1993). The Relationship Between Public and Private Investment. The Jerome Levy Economics Institute of Bard College and Eastern Michigan University, Working Paper no 85.

FEE. Fundaçáo de Economia e Estatística do Rio Grande do Sul. Disponível em: http://feedados.fee.tche.br/feedados/. Acesso em: 25/03/2015.

FEE. Fundação de Economia e Estatística do Rio Grande do Sul. Carta de Conjuntura: Divulgaçáo do PIB do segundo trimestre de 2015. http://www.fee.rs.gov.br/pib/ desempenho-poisitivo-agropecuaria-evita-queda-maior/. Acesso em: 09/09/2015.

FERREIRA, P. C. (1996). Investimento em infra-estrutura no Brasil: fatos estilizados e relaçóes de longo prazo. Pesquisa e Planejamento Econômico, V. 26, n. 2, p. 231-252, 1996. 
FERREIRA, P.; MALLIAGROS, T. (1998). Impactos produtivos da infraestrutura no Brasil -1950/1995. Pesquisa e Planejamento Econômico, V. 28, n. 2, p. 315-38.

FIGUEIREDO, L.; NORONHA, K. V.; ANDRADE, M. V. (2003). Os impactos da saúde sobre o crescimento econômico na década de 90: uma análise para os estados brasileiros. Textos para discussáo n. 219. Belo Horizonte: UFMG/Cedeplar.

FIRME, V. A. C.; FREGUGLIA, R. S. (2013). Análise do crescimento dos municípios brasileiros utilizando dados em painel e controles espaciais sobre o modelo de Mankiw, Romer e Weil (1992) para o período de 1980 a 2010. In: Anais do XIX Fórum BNB / XVIII ANPEC Nordeste.

HERRERA, S. e BLANCO, F. (2006). The quality of fiscal adjustment and the longrun growth impact of fiscal policy in Brazil, In: Anais do XXXIV Encontro Nacional de Economia - ANPEC, Salvador/BA.

JOHNSTON, J.; DINARDO, J. (1997). Econometric Methods, 4a edição. MC Graw Hill, New York.

KORMENDI, R. C.; MEGUIRE, P. G. (1985). Macroeconomic determinants of growth. Journal of Monetary Econometrics. Vol.16, p.141-163.

LINDAUER, D. L.; VELENCHIK, A. D. (1992). Government spending in developing countries: trends, causes and determinants. World Bank Research Observer, V. 7, p. 5978.

LUCAS, R. (1988). On the Mechanics of Economic Development. Journal of Monetary Economics, V. 22, n.1, p.3-42.

MUSGRAVE, R. A. e MUSGRAVE, P. B. (1980). Finanças Públicas: teoria e prática. São Paulo: Campus.

OLIVEIRA, C. A. de. (2006). Política fiscal local e o crescimento econômico dos municípios gaúchos (1996 - 2001). In: Anais do III Encontro de Economia Gaúcha. Porto Alegre/RS.

OLIVEIRA, C. A.; JACINTO, P. A.; MARQUES. (2009). O papel da política fiscal local no crescimento econômico de cidades: uma evidência empírica para o Brasil. Revista Economia, Brasilia. V. 10, n. 1, p. 49-68.

PEREIRA, F. M, ELLERY, R. G. (2011). Política fiscal, choques externos e ciclos econômicos no Brasil. Disponível em: http://www.anpec.org.br/revista/vol12/ vol12n3p445_474.pdf. Acesso em: 22/03/2015. 
RAM, R. (1986). Government Size and Economic Growth: a New Framework and Some Evidence from Cross-Section and Time-Series Data. American Economic Review. V. 76, p. 191-203.

ROCHA, F., GIUBERTI, A. C. (2008). Assimetria cíclica na política fiscal dos estados brasileiros. Pesquisa e Planejamento Econômico, V. 38, n.2, p.253-275.

ROCHA, F., GIUBERTI, A. C. (2007). Composição do gasto público e crescimento econômico: uma avaliação macroeconômica da qualidade dos gastos dos estados brasileiros. Economia Aplicada, São Paulo. V. 11, p. 463-485.

ROMER, P. (1990). Endogenous Technological Change. Journal of Political Economy, V. 98, n.5, p.S71-S102. October.

ROMER, P. (1986). Increasing Returns and Long-Run Growth. Journal of Political Economy, V. 94, n.5, p.1002-37.

ROMER, D. (1996). Advanced Macroeconomics. Nova York: McGraw-Hill.

SEFAZ. Secretaria da Fazenda do Estado do Rio Grande do Sul. www.sefaz.rs.gov.br. Acesso em: 15/02/2016.

SOLOW. R. M. A. (1956). Contribution to the theory of economic growth. The Quarterly Journal of Economics, p. 65-94.

SUMMERS, R.; HESTON, A. (1988). A new set of international comparisons of real product and price levels. Estimates for 130 countries. Review of Income and Wealth, V. 34 , p. $1-25$.

SRINIVASAN, T. (1985). Neoclassical Political Economy, the State, and Economic Development. Asian Development Review, V. 3, n. 2, p.38-58.

SWAN, T. W. (1956). Economic Growth and Capital Accumulation. The Economic Record, V. 32, p. 334-61. November.

WAGNER, A. (1983). Three Extracts on Public Finance, London: Macmillan. 
Anexo 1: Síntese da literatura nacional sobre crescimento econômico e gastos
públicos públicos

\begin{tabular}{|c|c|c|c|c|}
\hline Autores & $\begin{array}{l}\text { Unidade } \\
\text { regional }\end{array}$ & Objetivo & Metodologia & Principais resultados \\
\hline $\begin{array}{l}\text { Arraes } \\
\text { e Teles } \\
(2000)\end{array}$ & $\begin{array}{c}\text { Municípios } \\
\text { brasileiros }\end{array}$ & $\begin{array}{l}\text { Estudam os efeitos } \\
\text { de políticas fiscais } \\
\text { sobre o crescimento } \\
\text { econômico no } \\
\text { período } 1981 \text { a } \\
1995 \\
\end{array}$ & $\begin{array}{l}\text { Dados em } \\
\text { painel }\end{array}$ & $\begin{array}{l}\text { Os gastos em educação e cultura } \\
\text { e, em seguida, em saúde e } \\
\text { saneamento e em transportes, } \\
\text { sáo os mais positivos sobre o } \\
\text { crescimento econômico das cinco } \\
\text { regiôes brasileiras. }\end{array}$ \\
\hline $\begin{array}{c}\text { Rocha e } \\
\text { Giuberti } \\
(2007)\end{array}$ & $\begin{array}{c}\text { Estados } \\
\text { brasileiros }\end{array}$ & $\begin{array}{l}\text { Analisam o efeito } \\
\text { da composiçáo dos } \\
\text { gastos públicos } \\
\text { sobre o crescimento } \\
\text { da renda per capita } \\
\text { a nível estadual, } \\
\text { entre } 1986 \text { e } 2002\end{array}$ & $\begin{array}{c}\text { Dados em } \\
\text { painel }\end{array}$ & $\begin{array}{l}\text { Os gastos de capital aparecem } \\
\text { como produtivos, enquanto que } \\
\text { os gastos correntes são produtivos } \\
\text { até um limite de } 61 \% \text { da despesa } \\
\text { orçamentária. Os gastos com } \\
\text { transporte, comunicação e defesa } \\
\text { também contribuem para o } \\
\text { crescimento dos estados. }\end{array}$ \\
\hline $\begin{array}{c}\text { Figueiredo } \\
\text { et al. } \\
(2003)\end{array}$ & $\begin{array}{c}\text { Estados } \\
\text { brasileiros }\end{array}$ & $\begin{array}{l}\text { Investigam a relação } \\
\text { entre provisão } \\
\text { de saúde e taxa } \\
\text { de crescimento } \\
\text { entre os estados } \\
\text { brasileiros, no } \\
\text { período } 1991-2000\end{array}$ & $\begin{array}{c}\text { Dados em } \\
\text { painel }\end{array}$ & $\begin{array}{l}\text { A maior provisão de saúde, } \\
\text { relaciona-se positivamente com } \\
\text { o crescimento da renda per } \\
\text { capita das unidades federativas, } \\
\text { isso ocorre de maneira indireta, } \\
\text { através do estímulo à acumulação } \\
\text { de capital humano através de sua } \\
\text { relaçáo com a escolaridade. }\end{array}$ \\
\hline $\begin{array}{l}\text { Oliveira } \\
(2006)\end{array}$ & $\begin{array}{l}\text { Municípios } \\
\text { gaúchos }\end{array}$ & $\begin{array}{c}\text { Estudou o } \\
\text { impacto da } \\
\text { política fiscal local } \\
\text { no crescimento } \\
\text { econômico dos } \\
\text { municípios do Rio } \\
\text { Grande do Sul } \\
\end{array}$ & $\begin{array}{c}\text { Dados } \\
\text { cross-section } \\
\text { espacial }\end{array}$ & $\begin{array}{l}\text { Os gastos públicos locais } \\
\text { relacionaram-se positivamente } \\
\text { com o crescimento econômico } \\
\text { dos municípios gaúchos, } \\
\text { principalmente os gastos com } \\
\text { investimentos e educaçáo. }\end{array}$ \\
\hline $\begin{array}{l}\text { Oliveira et } \\
\text { al. (2009) }\end{array}$ & $\begin{array}{c}\text { Municípios } \\
\text { brasileiros }\end{array}$ & $\begin{array}{l}\text { Analisam } \\
\text { empiricamente o } \\
\text { papel da política } \\
\text { fiscal local no } \\
\text { crescimento } \\
\text { econômico das } \\
\text { cidades brasileiras. }\end{array}$ & $\begin{array}{c}\text { Dados cross- } \\
\text { section }\end{array}$ & $\begin{array}{l}\text { Os resultados mostram que o } \\
\text { governo local tem um importante } \\
\text { papel no crescimento econômico } \\
\text { das cidades e que os investimentos } \\
\text { públicos se mostraram eficientes } \\
\text { e afetaram positivamente o } \\
\text { crescimento econômico. }\end{array}$ \\
\hline
\end{tabular}




\begin{tabular}{|c|c|c|c|c|}
\hline Autores & $\begin{array}{l}\text { Unidade } \\
\text { regional }\end{array}$ & Objetivo & Metodologia & Principais resultados \\
\hline $\begin{array}{l}\text { Dassow et } \\
\text { al. }(2011)\end{array}$ & $\begin{array}{l}\text { Municípios } \\
\text { mato- } \\
\text { grossenses }\end{array}$ & $\begin{array}{l}\text { Estudam o } \\
\text { crescimento } \\
\text { econômico dos } \\
\text { municípios do } \\
\text { Mato Grosso de } \\
2001 \text { a } 2007\end{array}$ & $\begin{array}{c}\text { Dados } \\
\text { em painel } \\
\text { espacial }\end{array}$ & $\begin{array}{c}\text { Os autores evidenciaram } \\
\text { dependência espacial nas taxas } \\
\text { de crescimento e composiçóes } \\
\text { setoriais da renda per capita } \\
\text { no valor adicionado total, } \\
\text { encontraram convergência absoluta } \\
\text { e condicional da renda nos } \\
\text { municípios mato-grossenses. }\end{array}$ \\
\hline $\begin{array}{l}\text { Divino } \\
\text { e Junior } \\
(2012)\end{array}$ & $\begin{array}{l}\text { Municípios } \\
\text { brasileiros }\end{array}$ & $\begin{array}{l}\text { Averiguam o efeito } \\
\text { da composiçáo dos } \\
\text { gastos públicos } \\
\text { (corrente e de } \\
\text { capital) sobre o } \\
\text { crescimento da } \\
\text { renda per capita } \\
\text { dos municípios } \\
\text { brasileiros no } \\
\text { período 1991-2000 }\end{array}$ & $\begin{array}{c}\text { Dados em } \\
\text { painel }\end{array}$ & $\begin{array}{l}\text { Os resultados mostram um efeito } \\
\text { positivo dos gastos públicos sobre } \\
\text { crescimento econômico municipal } \\
\text { e que os municípios com renda } \\
\text { abaixo da linha de pobreza, têm } \\
\text { uma necessidade maior de gastos } \\
\text { correntes do que os que estấo } \\
\text { acima dessa linha. }\end{array}$ \\
\hline $\begin{array}{c}\text { Firme e } \\
\text { Freguglia } \\
(2013)\end{array}$ & $\begin{array}{l}\text { Municípios } \\
\text { brasileiros }\end{array}$ & $\begin{array}{l}\text { Analisam os } \\
\text { condicionantes } \\
\text { do crescimento } \\
\text { dos municípios } \\
\text { brasileiros entre } \\
1980 \text { a } 2010\end{array}$ & $\begin{array}{c}\text { Dados cross- } \\
\text { section } \mathrm{e} \\
\text { painel }\end{array}$ & $\begin{array}{l}\text { O crescimento dos municípios é } \\
\text { afetado por seus vizinhos. Com } \\
\text { relação aos modelos de painel, os } \\
\text { de efeitos fixos e primeira diferença } \\
\text { foram preferíveis e mostraram } \\
\text { que o impacto do capital humano } \\
\text { direto e indireto, é maior que o } \\
\text { impacto do capital físico para os } \\
\text { municípios brasileiros. }\end{array}$ \\
\hline $\begin{array}{l}\text { Costa et } \\
\text { al. }(2013)\end{array}$ & $\begin{array}{l}\text { Municípios } \\
\text { nordestinos }\end{array}$ & $\begin{array}{l}\text { Estudam o } \\
\text { impacto da } \\
\text { política fiscal local } \\
\text { no crescimento } \\
\text { econômico dos } \\
\text { municípios do } \\
\text { Nordeste }\end{array}$ & $\begin{array}{c}\text { Dados } \\
\text { cross-section } \\
\text { espacial }\end{array}$ & $\begin{array}{l}\text { Explicitam que os gastos públicos } \\
\text { se relacionaram positivamente } \\
\text { com o crescimento econômico } \\
\text { dos municípios nordestinos, } \\
\text { destacando-se os dispêndios com } \\
\text { educaçáo e saúde. }\end{array}$ \\
\hline
\end{tabular}

Fonte: Elaboração dos autores a partir de trabalhos empíricos aplicados ao Brasil. 